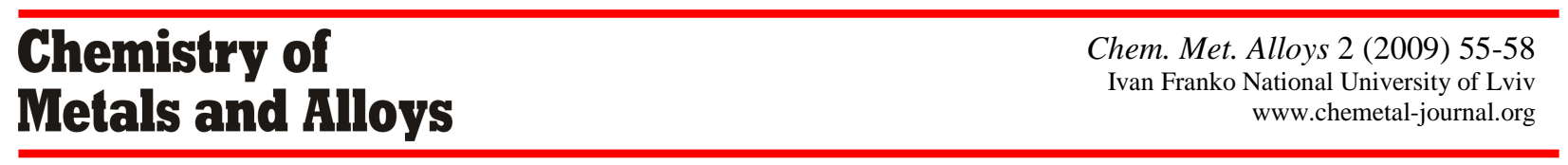

\title{
Phase diagram of the $\mathrm{CdGa}_{2} \mathrm{Se}_{4}-\mathrm{Sb}_{2} \mathrm{Se}_{3}$ system and single crystal growth of $\mathrm{CdGa}_{2} \mathrm{Se}_{4}$
}

\author{
S.M. SOSOVSKA ${ }^{1}$, O.M. YURCHENKO ${ }^{1}$, Y.E. ROMANYUK ${ }^{2}$, I.D. OLEKSEYUK ${ }^{1}$, O.V. PARASYUK ${ }^{1 *}$ \\ ${ }^{1}$ Department of General and Inorganic Chemistry, Volyn State University, Voli Ave 13, 43025 Lutsk, Ukraine \\ ${ }^{2}$ Swiss Federal Laboratories for Materials Testing and Research, CH-8600 Dübendorf, Switzerland \\ * Corresponding author.Tel.:+38-03322-49972; fax:+38-03322-41007; e-mail: oleg@univer.lutsk.ua
}

Received April 1, 2009; accepted June 30, 2009; available on-line November 16, 2009

The phase diagram of the $\mathrm{CdGa}_{2} \mathrm{Se}_{4}-\mathrm{Sb}_{2} \mathrm{Se}_{3}$ system was investigated by differential-thermal analysis, powder $X$-ray diffraction, and metallography. The system is of the eutectic type with coordinates of the eutectic point $\sim 88 \mathrm{~mol} . \% \mathrm{Sb}_{2} \mathrm{Se}_{3}$ and $835 \mathrm{~K}$. From the constructed phase diagram, an optimum concentration of the $\mathrm{Sb}_{2} \mathrm{Se}_{3}$ solvent was selected, and single crystals of $\mathrm{CdGa}_{2} \mathrm{Se}_{4}$ were grown by the solution-melt method. Absorption spectra of the grown crystals were studied. The estimated optical band gap is $1.95 \pm 0.05 \mathrm{eV}$. A weak absorption band at 1.5-1.7 $\mathrm{eV}$ is attributed to the antimony impurity.

Inorganic Materials / Crystal Growth / X-ray diffraction / Phase diagram / Thermal analysis

\section{Introduction}

Among complex semiconductors with a diamond-like structure, defect ternary compounds $\mathrm{A}^{\mathrm{II}} \mathrm{B}^{\mathrm{III}}{ }_{2} \mathrm{C}^{\mathrm{VI}}{ }_{4}$ are of a high interest because of the presence of so-called stoichiometric vacancies. Moreover, these compounds exhibit a very low sensitivity to unwanted impurities and a high resistance against ionization radiation. The $\mathrm{CdGa}_{2} \mathrm{Se}_{4}$ compound belongs to the wide-gap semiconductors, and is known as a luminescent and photosensitive material [1,2]. Its optical properties were studied in [1,3-8], both on thin films and bulk crystals. The energy gap was reported to be $2.41 \mathrm{eV}$ [3], $2.51 \mathrm{eV}$ [4], or $2.33 \mathrm{eV}$ [5]. The low-temperature (LT) modification of $\mathrm{CdGa}_{2} \mathrm{Se}_{4}$ crystallizes in the tetragonal structure of cadmium thiogallate or defect chalcopyrite (space group $I \overline{4}, \quad a=0.5743$, $c=1.0756 \mathrm{~nm}$ [9]). However, its practical application is hindered by technological difficulties in producing high-quality bulk crystals. Although $\mathrm{CdGa}_{2} \mathrm{Se}_{4}$ is formed congruently, it possesses a polymorphous transformation [10,11], which complicates the growth of single crystals from the stoichiometric melt.

Previously, $\mathrm{CdGa}_{2} \mathrm{Se}_{4}$ single crystals were grown by the chemical vapor transport (CVT) method, directional crystallization of the stoichiometric melt, or crystallization from non-stoichiometric solutions. The CVT method was reported in $[12,13]$. In both cases, iodine was used as transport agent with a concentration of $5 \mathrm{mg} / \mathrm{ml}$. The ratio between the temperature in the evaporation/condensation zone was $1173 / 1023 \mathrm{~K}$ in [12] (crystals up to $4 \times 1 \times 1 \mathrm{~mm}^{3}$ ), or $1093 / 853 \mathrm{~K}$ in [13] (crystal length $10 \div 15 \mathrm{~mm}$ ). A two- zone furnace, keeping $1200-1170 \mathrm{~K}$ in the crystallization zone and $870-920 \mathrm{~K}$ in the annealing zone, was employed for the directional crystallization of the stoichiometric melt [14]. The temperature gradient at the crystallization front was $10 \mathrm{~K} / \mathrm{cm}$, whereas the rate at which the growth container was moved down was $0.5 \mathrm{~mm} / \mathrm{h}$. Under these conditions, single crystal blocks of $10 \times 5 \times 5 \mathrm{~mm}^{3}$ were obtained. Single crystal growth of $\mathrm{CdGa}_{2} \mathrm{Se}_{4}$ was also performed using non-stoichiometric melts of the ternary compound with $\mathrm{GeSe}_{2}, \mathrm{SnSe}_{2}$, or $\mathrm{SnSe}$ [15-17]. The composition of the initial charges was selected from the field of primary crystallization of the LTmodification of $\mathrm{CdGa}_{2} \mathrm{Se}_{4}$. The grown crystals were up to $25 \mathrm{~mm}$ in length and $14 \mathrm{~mm}$ in diameter. However, a drawback of the used solvents is their incorporation in the lattice of the growing crystal (according to the constructed phase diagrams, the solid solution range of $\mathrm{CdGa}_{2} \mathrm{Se}_{4}$ extends to $3 \div 4$ mol.\%). Therefore, the search for a suitable solvent for the $\mathrm{CdGa}_{2} \mathrm{Se}_{4}$ crystal growth is a challenging task.

In this study, we investigate the phase diagram of the $\mathrm{CdGa}_{2} \mathrm{Se}_{4}-\mathrm{Sb}_{2} \mathrm{Se}_{3}$ system and demonstrate the potential of $\mathrm{CdGa}_{2} \mathrm{Se}_{4}$ single crystal growth employing $\mathrm{Sb}_{2} \mathrm{Se}_{3}$ as solvent.

\section{Experimental}

The alloys for the investigation of the $\mathrm{CdGa}_{2} \mathrm{Se}_{4}-$ $\mathrm{Sb}_{2} \mathrm{Se}_{3}$ phase equilibria were prepared from highpurity elements: $\mathrm{Cd}-99.9999$ wt.\%, Ga - 
99.9997 wt.\%, $\mathrm{Sb}-99.99$ wt.\%, and $\mathrm{Se}-$ 99.997 wt.\%. The synthesis was performed by alloying calculated amounts of elements in evacuated quartz ampoules. The ampoules were heated to $1273 \mathrm{~K}$ at a rate of $40-50 \mathrm{~K} \cdot \mathrm{h}^{-1}$, held at the maximum temperature for 6 hours, and then cooled down to room temperature at a rate of $10 \mathrm{~K} \cdot \mathrm{h}^{-1}$.

The obtained alloys were investigated by differential-thermal analysis (DTA), X-ray diffraction (XRD) and metallography. DTA curves were recorded on a Paulik-Paulik-Erdey derivatograph with a Pt/Pt$\mathrm{Rh}$ thermocouple. The XRD patterns were obtained on powders using a DRON 4-13 diffractometer with $\mathrm{CuK}_{\alpha}-$ radiation. The microstructure of the alloys was observed on a Leica VMHT Auto microhardness tester.

\section{Results}

\section{Phase diagram of the CdGa $\mathrm{Se}_{4}-\mathrm{Sb}_{2} \mathrm{Se}_{3}$ system}

The $\mathrm{CdGa}_{2} \mathrm{Se}_{4}-\mathrm{Sb}_{2} \mathrm{Se}_{3}$ system is quasi-binary, of the eutectic type (Fig. 1). Its liquidus consists of three fields of primary crystallization: high- (HT) and LTmodifications of $\mathrm{CdGa}_{2} \mathrm{Se}_{4}$, and $\mathrm{Sb}_{2} \mathrm{Se}_{3}$. The coordinates of the eutectic point, estimated by constructing a Tamman triangle, are $\sim 88 \mathrm{~mol} . \%$ $\mathrm{Sb}_{2} \mathrm{Se}_{3}$ and $835 \mathrm{~K}$. A non-variant horizontal at $1087 \mathrm{~K}$ corresponds to the phase transformation of $\mathrm{CdGa}_{2} \mathrm{Se}_{4}$. A small temperature decrease indicates the peritectic process $\mathrm{L}+\alpha \Leftrightarrow \alpha^{\prime}$, which corresponds to the horizontal. Investigation of the sub-solidus region showed that the solid solution ranges of the system components do not exceed 2 mol. $\%$.

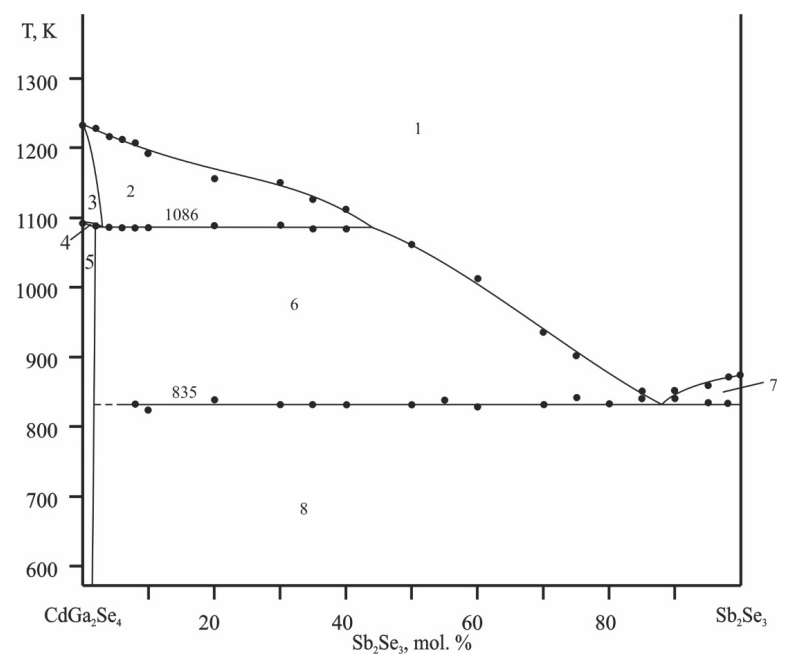

Fig. 1 Phase diagram of the $\mathrm{CdGa}_{2} \mathrm{Se}_{4}-\mathrm{Sb}_{2} \mathrm{Se}_{3}$ system: (1) L; (2) L+ $\alpha$; (3) $\alpha$; (4) $\alpha+\alpha^{\prime}$; (5) $\alpha^{\prime}$; (6) $\mathrm{L}+\alpha^{\prime}$; (7) $\mathrm{L}+\mathrm{Sb}_{2} \mathrm{Se}_{3}$; (8) $\alpha^{\prime}+\mathrm{Sb}_{2} \mathrm{Se}_{3}$.
For instance, an alloy containing 2 mol.\% of $\mathrm{Sb}_{2} \mathrm{Se}_{3}$ is already a two-phase one (Fig. 2a). Dark grains, which occupy the major part of the metallographic section, belong to $\mathrm{CdGa}_{2} \mathrm{Se}_{4}$. Small eutectic inclusions are visible at grain borders. With increasing $\mathrm{Sb}_{2} \mathrm{Se}_{3}$ content, the size of the primary grains of the ternary compound gradually decreases, whereas the eutectic fields enlarge (e.g. the alloy with 50 mol.\% $\mathrm{Sb}_{2} \mathrm{Se}_{3}$ in Fig. 2b). The alloy with 90 mol.\% $\mathrm{Sb}_{2} \mathrm{Se}_{3}$ is closest to the eutectic point (Fig. 2c). Further increase of the $\mathrm{Sb}_{2} \mathrm{Se}_{3}$ content leads to inversion of the primary crystallization. A typical microsection of the alloy containing 95 mol.\% $\mathrm{Sb}_{2} \mathrm{Se}_{3}$ is shown in Fig. 2d. The light grains represent the binary compound, which is surrounded by eutectic fields.

Some typical XRD patterns of the alloys are shown in Fig. 3. All of them exhibit sharp diffraction peaks. The alloy corresponding to the $\mathrm{CdGa}_{2} \mathrm{Se}_{4}$ compound was indexed in the structure of defect chalcopyrite, space group $I \overline{4}$ with lattice parameters $a=0.57430(6)$ and $c=1.0752(2) \mathrm{nm}$, which is in good agreement with reported data [18]. A diffraction pattern of the $\mathrm{Sb}_{2} \mathrm{Se}_{3}$ alloy was indexed in an orthorhombic structure (space group Pbnm) with lattice parameters $a=1.1619(2), \quad b=1.1767(2)$, $c=0.39718(6) \mathrm{nm}$, which are close to those in [19]. Diffraction patterns of the intermediate alloys exhibit a mixture of two sets of diffraction reflections, which belong to the system components. The lattice parameters of the components, calculated for the intermediate alloys, do not differ from those obtained for pure $\mathrm{CdGa}_{2} \mathrm{Se}_{4}$ or $\mathrm{Sb}_{2} \mathrm{Se}_{3}$.

\section{Single crystal growth of $\mathrm{CdGa}_{2} \mathrm{Se}_{4}$}

Since the system liquidus includes a field of primary crystallization of $\mathrm{LT}-\mathrm{CdGa}_{2} \mathrm{Se}_{4}$, this concentration range can be used for the growth of $\mathrm{LT}-\mathrm{CdGa}_{2} \mathrm{Se}_{4}$ crystals. In this work we employed an initial charge containing $50 \mathrm{~mol} \% \mathrm{Sb}_{2} \mathrm{Se}_{3}$. The charge of $15 \mathrm{~g}$ was synthesized according the procedure described above. Afterwards, it was ground into fine powder and transferred into a conical quartz ampoule, which was then evacuated and soldered. The single crystal growth was performed in a two-zone furnace with a constant temperature profile. The temperature of the upper zone was $1273 \mathrm{~K}$, and the temperature of the lower zone varied from 870 to $1220 \mathrm{~K}$. After charge melting, the ampoule was moved down at a rate of $5 \mathrm{~mm} /$ day to crystallize $4-5 \mathrm{~mm}$ of the melt. The recrystallization annealing lasted for 100 hours. Later, first 2-3 $\mathrm{mm}$ of the seed was melted back, and the crystal was growing by slow $(2-3 \mathrm{~mm} /$ day) moving of the growth container down to the colder zone. When using higher rates, we observed incorporation of residual eutectic between single crystal blocks, which, apparently, was due to the high viscosity of the solution and slow equalization of component concentrations in the melt. The temperature gradient at 
S.M. Sosovska et al., Phase diagram of the $\mathrm{CdGa}_{2} \mathrm{Se}_{4}-\mathrm{Sb}_{2} \mathrm{Se}_{3}$ system and single crystal growth of $\mathrm{CdGa}_{2} \mathrm{Se}_{4}$

Table 1 The stoichiometric and experimental composition of $\mathrm{CdGa}_{2} \mathrm{Se}_{4}$ single crystals measured by EDX.

\begin{tabular}{ccc}
\hline Element & stoichiometric (at.\%) & experimental (at.\%) \\
$\mathrm{Cd}$ & 14.29 & 14.23 \\
$\mathrm{Ga}$ & 28.57 & 27.67 \\
$\mathrm{Se}$ & 57.14 & 58.10 \\
\hline
\end{tabular}

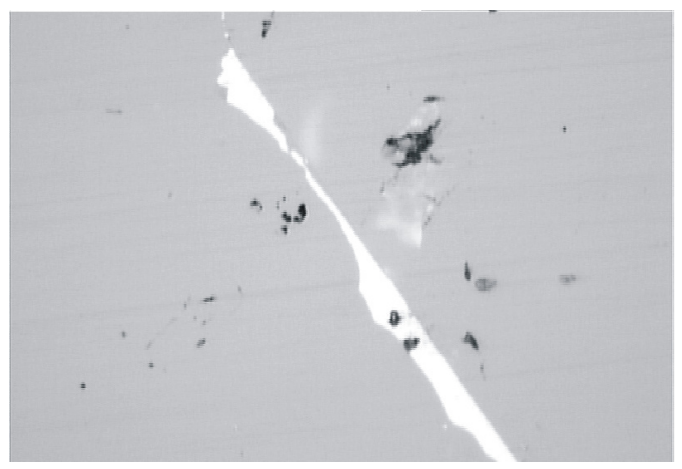

(a)

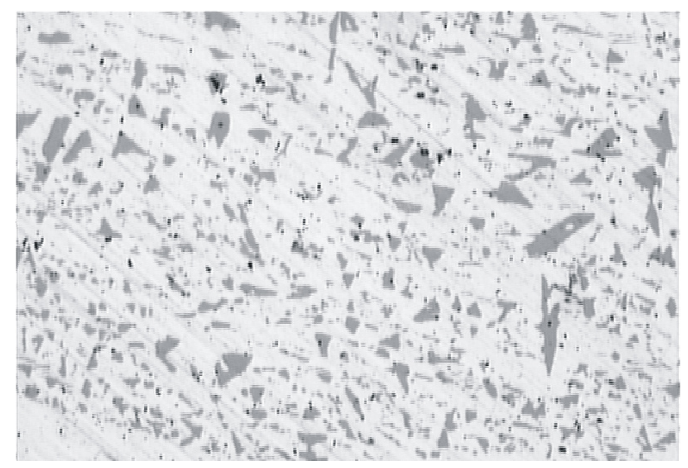

(c)

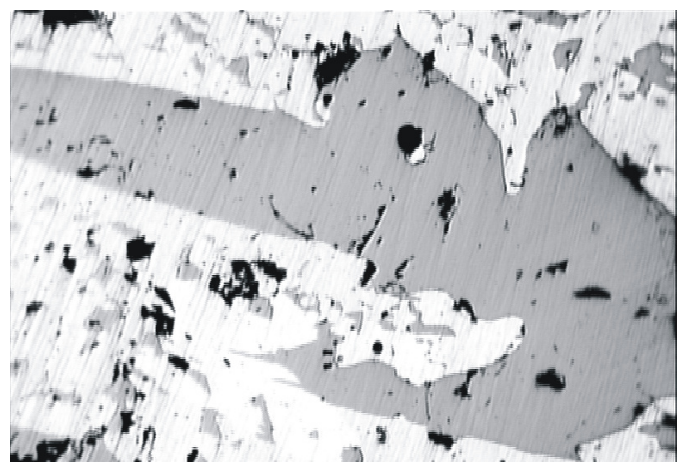

(b)

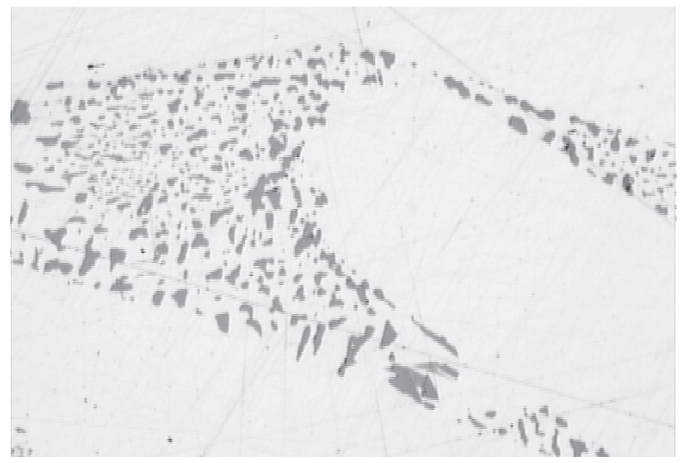

(d)

Fig. 2 Optical photographs of some microsections of the $\mathrm{CdGa}_{2} \mathrm{Se}_{4}-\mathrm{Sb}_{2} \mathrm{Se}_{3}$ system (composition in mol.\% $\left.\mathrm{Sb}_{2} \mathrm{Se}_{3}\right)$ : (a) 2, (b) 50, (c) 90, (d) $95\left(320 \times 240 \mu \mathrm{m}^{2}\right)$.

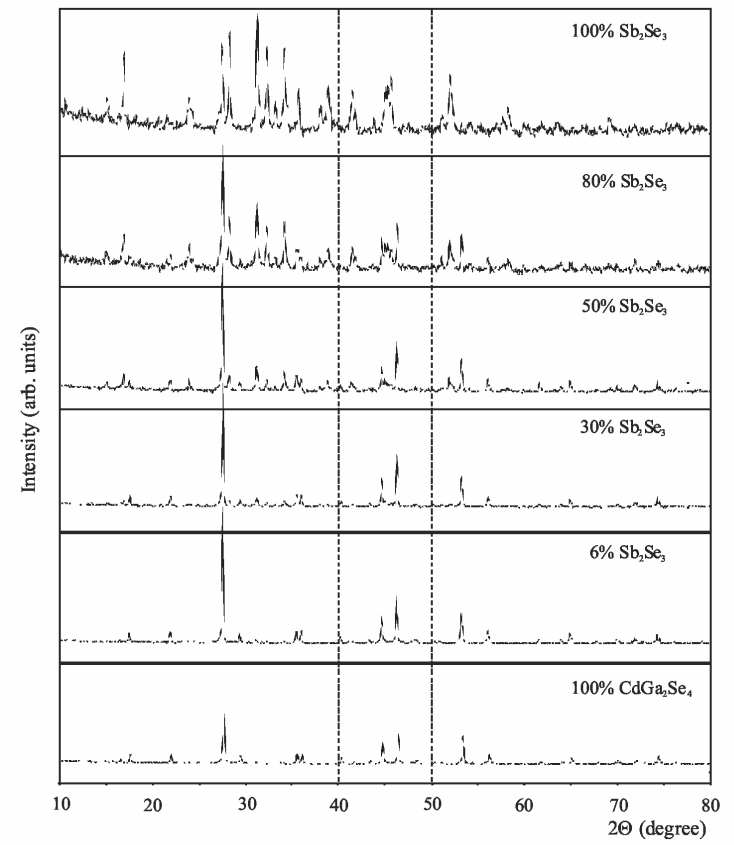

Fig. 3 Typical XRD patterns of the alloys of the $\mathrm{CdGa}_{2} \mathrm{Se}_{4}-\mathrm{Sb}_{2} \mathrm{Se}_{3}$ system. the crystallization front varied from 12 to $35 \mathrm{~K} / \mathrm{cm}$. After complete crystallization, the furnace was cooled to room temperature at a rate of $5 \mathrm{~K} \cdot \mathrm{h}^{-1}$.

The grown boule consisted of two parts. The lower (cone) part was the single crystal of the ternary phase (in most cases several single crystal blocks), and the top part was the solidified eutectic (LT-CdGa $\mathrm{Se}_{4}+\mathrm{Sb}_{2} \mathrm{Se}_{3}$ ). The length of the single crystal part was about $15-20 \mathrm{~mm}$, depending on the diameter of the growth container and the sharpness of its cone.

The composition of the grown crystal was examined on a Philips XL 30 FEG scanning electron microscope with excitation energy of $20 \mathrm{keV}$. The Oxford Instruments INCA software package was used for energy-dispersive X-ray analysis (EDX) quantification. The obtained results are shown in Table 1 together with the expected stoichiometric concentrations for the $\mathrm{CdGa}_{2} \mathrm{Se}_{4}$ composition. Only three principal elements and no antimony impurities could be detected by EDX. However, the red color of the grown crystals, which is different from the expected orange color of $\mathrm{CdGa}_{2} \mathrm{Se}_{4}$, indicated a small (less than $2 \mathrm{~mol} . \%$ ) solubility of $\mathrm{Sb}_{2} \mathrm{Se}_{3}$ in the 


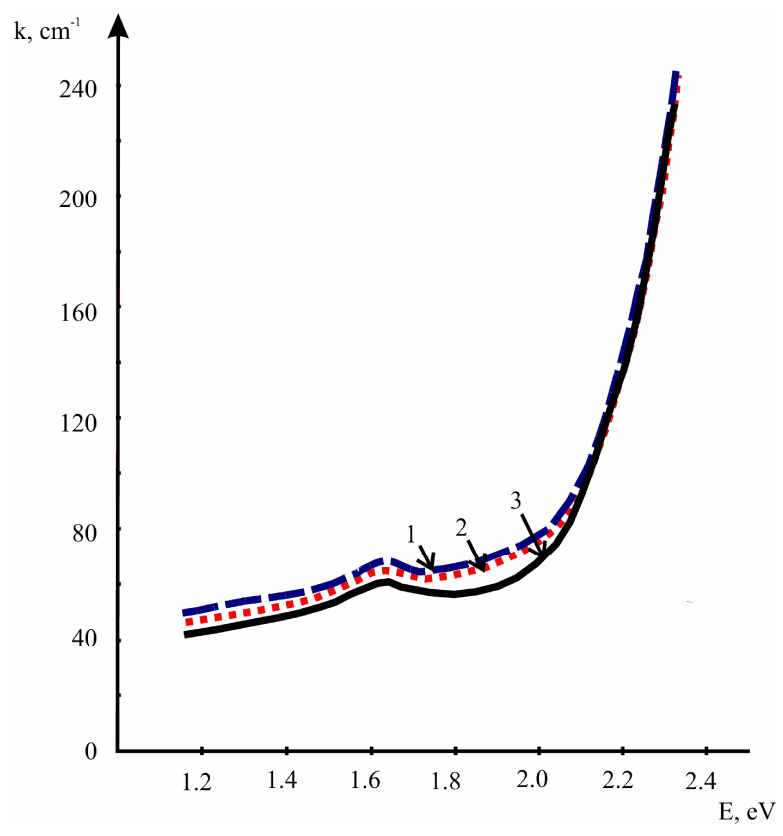

Fig. 4 Room-temperature optical absorption spectra of $\mathrm{CdGa}_{2} \mathrm{Se}_{4}$ single crystal plates cut from different parts of the crystal boule: (1) lower, (2) middle, and (3) upper part.

$\mathrm{CdGa}_{2} \mathrm{Se}_{4}$ crystals. This fact was also taken into account when constructing the phase diagram.

\section{Absorption spectra of the $\mathrm{CdGa}_{2} \mathrm{Se}_{4}$ single crystal}

We investigated absorption spectra of the grown $\mathrm{CdGa}_{2} \mathrm{Se}_{4}$ crystals. For that, the boule was cut perpendicular to the growth direction into several plates. The absorption was measured with a spectrofluorimeter CM-2203. Fig. 4 presents the spectral distribution of absorption coefficients for plates cut from the lower (sample 1), middle (2), and upper (3) parts of the boule. A diffused absorption band in the range $1.5-1.7 \mathrm{eV}$, centered at $1.63 \mathrm{eV}$, is observed for all samples. Its intensity does not depend on the nature of the sample. Likely, this band can be attributed to the impurity levels formed by antimony atoms. The absorption coefficient slightly decreases from the lower to the upper part of the boule, but remains in the range $40-63 \mathrm{~cm}^{-1}$. The optical band gap at $298 \mathrm{~K}$, directly measured from the absorption spectra, is $1.95 \pm 0.05 \mathrm{eV}$. This value is significantly different from the energy gap of undoped $\mathrm{CdGa}_{2} \mathrm{Se}_{4}$ [3-5], which also indicates a certain solid solution range of the ternary compound.

\section{References}

[1] S.I. Radautsan, V.F. Zhitar', I.G. Kosnichan, M.I. Shmiglyuk, Fiz. Tekh. Poluprovodn. 5(11) (1972) 1959.

[2] C.-D. Kim, H.-M. Jeong, J. Korean Phys. Soc. 27(4) (1994) 440.

[3] G.B. Abdullaev, V.G. Agaev, V.B. Antonov, R.Kh. Nani, E.Yu. Salaev, Fiz. Tekh. Poluprovodn. 5(11) (1971) 3132.

[4] S.T. Kshirsagar, Thin Solid Films 45 (1977) L5.

[5] A.M. Salem, J. Phys. D: Appl. Phys. 36 (2003) 1030.

[6] C.-D. Kim, T.-S. Cho, W.-T. Kim, Solid State Commun. 63(9) (1987) 871.

[7] L.N. Streltsov, V.Ya. Chernykh, V.M. Petrov, Fiz. Tekh. Poluprovodn. 1 (1967) 656.

[8] D.A. Guseinova, T.G. Kerimova, R.Kh. Nami, Fiz. Tekh. Poluprovodn. 11 (1977) 1135.

[9] V. Krämer, D. Siebert, S. Febbraro, Z. Kristallogr. 169 (1984) 283.

[10] M.P. Tyrziu, S.I. Radautsan, M.M. Markus, S.M. Kolosenko, Phys. Status Solidi A 3(4) (1970) K293.

[11] A.M. Loireau-Lozac'h, M. Guittard, J. Flahaut, Mater. Res. Bull. 20 (1985) 443.

[12] J.A. Beun, R. Nitsche, M. Lichtensteiger, Physica 27 (1961) 448.

[13] V. Tezlevan, I. Mushkutariu, S. Radantsan, V. Tsurkan, Proc. $1^{\text {st }}$ Int.Conf. Material Science of Chalcogenide and Diamond-Structure Semiconductors, Chernivtsi, 1994, p. 28.

[14] A.A. Vaypolin, Y.A. Nikolaev, I.K. Polushina, V.Y. Rud', E.I. Terukov, N. Fernelius, Fiz. Tekh. Poluprovodn. 37(5) (2003) 572.

[15] I.D. Olekseyuk, O.V. Parasyuk, $1^{\text {st }}$ Int. Conf. Material Science of Chalcogenide and DiamondStructure Semiconductors, Chernivtsi, 1994, p. 111.

[16] O.V. Parasyuk, V.Z. Pankevych, O.M. Yurchenko, L.V. Piskach, I.D. Olekseyuk, Coll. Abstr. Open Ukr. Conf. for Young Researchers, Modern Problems in Material Science, Kharkiv, 2003, p. 97.

[17] I.D. Olekseyuk, O.V. Parasyuk, O.M. Yurchenko, L.V. Piskach, V.Z. Pankevych, Coll. Abstr. $4^{\text {th }}$ Int. Conf. Crystal Growth, Grenoble, 2004, p. 283.

[18] L. Gastaldi, M.G. Simeone, S. Viticoli, Solid State. Commun. 55 (1985) 605.

[19] M.-Z. Min, J.-P. Zhai, X.-Y. Wang, B.-P. Shen, G.-D. Wen, T. Fan, Chin. Sci. Bull. 43(5) (1998) 413. 